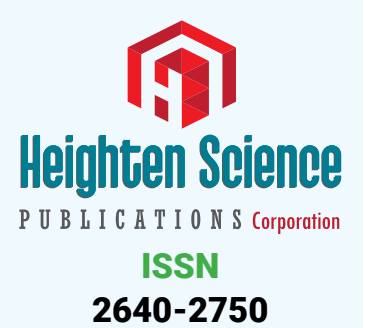

2640-2750
*Address for Correspondence: Mohammed Habib, MD, PhD, Alshifa Hospital, Cardiology Department, Gaza, Palestine, Tel: 00972599514060; Email: cardiomohammad@yahoo.com

Submitted: 22 May 2019

Approved: 06 June 2019

Published: 07 June 2019

Copyright: (c) 2019 Habib M, et al. This is an open access article distributed under the Creative Commons Attribution License, which permits unrestricted use, distribution, and reproduction in any medium, provided the original work is properly cited

Check for updates
Research Article

\section{Transcatheter Arterial Embolization for the treatment of upper gastrointestinal bleeding}

\author{
Mohammed Habib ${ }^{1 *}$ and Majed Alshounat ${ }^{2}$ \\ ${ }^{1}$ Consultant, Interventional Cardiologist, Head of Cardiology Department, Alshifa Hospital, Gaza, \\ Palestine \\ ${ }^{2}$ Consultant, interventional Cardiologist. Alshifa Hospital, Gaza, Palestine
}

\section{Abstract}

Background: Transcatheter arterial embolization can be used for patients with recurrent bleeding from the upper gastrointestinal tract after failed endoscopic treatment. Our aim to identify the clinical and technical factors that influenced the outcome of transcatheter embolization for therapy of upper gastrointestinal bleeding after failed surgery or after failed endoscopic treatment in high risk surgical patients.

Methods: We performed a prospective study to analysis of the 15 patients who underwent Transcatheter arterial embolization for nonvariceal upper gastrointestinal bleeding at Alshifa hospital from January 2015 to March 2019.

The following variables were recorded: demographic data, time from bleeding start to TAE, units of packed red cells before TAE and units of packed plasma before Transcatheter arterial embolization and we analysis 30 days rebleeding rates and mortality.

Results: Patients treated with Transcatheter arterial embolization (median age: 62 years, range: $14-79$ years). The technical success rate of the embolization procedure was $100 \%$. Time from bleeding start to TAE was 2.1 (1-4) days, units of packed red cells before Transcatheter arterial embolization was 12.8 (4-22) packed and units of packed plasma was 3.2 (2-5) packed. Following 30 days after embolization, 2 (13\%) patients had repeated bleeding and $3(20.0 \%)$ patients died.

Conclusion: In our experience, arterial embolization is a safe and effective treatment method for upper gastrointestinal bleeding and a possible alternative to surgery for high-risk patients.

\section{Introduction}

Acute nonvariceal upper gastrointestinal (GI) bleeding remains a challenging presentation due to significant morbidity and mortality rates, and about half of all cases of upper GI bleeding are caused by gastric and duodenal ulcers. Although firstline endoscopy achieves bleeding control in most patients, if this does not work, the mortality rate can be $5 \%$ to $10 \%$ because of multiple comorbidities, advanced age, and high transfusion requirements. However, hospitalization and mortality due to severe upper gastrointestinal bleeding as a result of peptic ulcer are still high among the elderly [1-4].

Surgery is also associated with high mortality, and therefore, selective transcatheter arterial embolization (TAE) is considered a safer alternative due to the avoidance of laparotomy, particularly in high-risk patients. In fact, in many institutions, TAE is now the first-line intervention for massive arterial bleeding from the upper GI tract that is resistant to endoscopic therapy. 
Arterial embolization in the upper GI tract above the ligament of Treitz is generally considered to be very safe because of the rich collateral supply to the stomach and duodenum.

We presents 15 cases of upper GIT bleeding treated successfully by arterial Embolization after failed endoscopy procedure.

\section{Methods}

From January 2015 to March 2019, 15 patients were referred to cardiac catheterization department with upper gastrointestinal bleeding. The typical candidate patient presents with the following:

1) massive bleeding (transfusion requirement of at least $3 \mathrm{U}$ blood over 24 hours) or hemodynamic compromise (systolic blood pressure $<90 \mathrm{~mm} \mathrm{Hg}$ and heart rate $>100$ beats per minute or clinical shock),

2) endoscopy-refractory acute UGI bleeding,

3) recurrent bleeding after surgery.

There are no absolute contraindications because angiography and embolization may be needed as lifesaving procedures.

One patient was transferred from pediatric surgery and diagnosis was traumatic liver injury due to AV fistula, 3 case transferred from general surgery and diagnosis was large liver hemangioma and liver cancer and 11 patients were transferred from internal medical department from Al Shifa hospital due to gastroduodenal ulcers, pancreatic cancer and liver pseudoaneurysm.

The following variables were recorded: demographic data, CT or endoscopic diagnoses, comorbidities, lowest hemoglobin levels, total transfusion requirements, postprocedure complications, and mortality rates.

\section{Result}

The median age was, 62 years (age range, 14-82 years). Female was 3 patients (20\%), The median time that passed from the clinical symptoms of bleeding to embolization was 4.2 days, 6 patients underwent multidetector computed tomography angiography (MDCTA) and 9 patient underwent endoscopy, For 1 patient, TAE was performed after failed endoscopic and surgical treatment due to duodenal ulcer, 6 patient underwent TAE because of high risk of surgery ( 2 liver cancer, 1 liver hemangioma, 1 pancreatic cancer, 1 right hepatic artery pseudoaneurysm after previous cholecystectomy, and 1 liver traumatic Arteriovenous fistula), and 8 patients TAE was performed after failed endoscopic intervention. Baseline patient characteristics and the amount of packed red blood cells and freshly frozen plasma administered to the patients before TAE are presented in table 1.

The most common of causes of bleeding are presented in table 2 . The most common causes of bleeding were bleeding from gastroduodenal ulcers ( 9 cases, $60 \%$ ), followed by bleeding from liver cancer of hemangioma (3 cases, 20\%) bleeding from pancreatic cancers ( 1 case, $6.7 \%)$, right hepatic artery pseudoaneurysm (1 case, $6.7 \%)$ and Liver traumatic AV fistula (1 case, $6.7 \%$ ) .

The technical success rate of the embolization procedure, which was defined as complete angiographic occlusion of the targeted vessels, was $100 \%$. Out of the 15 cases, 12 (80\%) were therapeutic embolizations, when the source of the bleeding was visualized during angiography, and $3(20 \%)$ were prophylactic embolizations of the anatomical site. The sites of embolization are presented in table 3. 


\begin{tabular}{|c|c|}
\hline Table 1: Patients baseline characteristics. & Variable \\
\hline Parameter & $12(80)$ \\
\hline Male, $n(\%)$ & $3(20)$ \\
\hline Female, $n(\%)$ & $62(14-79)$ \\
\hline Age: years (range) & $4.2(2: 7)$ \\
\hline Time from bleeding start to TAE: days(range) & $12.8(4-22)$ \\
\hline Units of packed red cells before TAE: packed (range) & $3.2(2-5)$ \\
\hline
\end{tabular}

\begin{tabular}{|c|c|c|}
\hline Table 2: Causes of GIT bleeding. & No & Percentage \\
\hline Causes & 9 & $60 \%$ \\
\hline Gastroduodenal ulcers & 2 & $13 \%$ \\
\hline Liver cancer & 1 & $6.7 \%$ \\
\hline Liver hemangioma & 1 & $6.7 \%$ \\
\hline Liver traumatic AV fistula & 1 & $6.7 \%$ \\
\hline Pseudoaneurysm & 1 & $6.7 \%$ \\
\hline Pancreatic cancer & 15 & $100 \%$ \\
\hline Total & & \\
\hline
\end{tabular}

\begin{tabular}{|c|c|c|}
\hline Embolized artery & No. & Percent \\
\hline Gastroduodenal artery & 7 & $47 \%$ \\
\hline Hepatic artery & 4 & $27 \%$ \\
\hline Left gastric artery & 3 & $20 \%$ \\
\hline Gastroduodenal artery and right gastroepiploic artery & 1 & $6.00 \%$ \\
\hline Total & 15 & $100 \%$ \\
\hline
\end{tabular}

No complications were reported after the procedure. Two (13\%) patients had an episode of rebleeding within 30 days after the embolization procedure, one patients after TAE were treated surgically, and another patient was treated by re-embolization.

Three $(20.0 \%)$ of the patients died. (One patient liver cancer, one patient pancreatic cancer and last patient right hepatic artery pseudoaneurysm)

Examples of the procedure are shown:

\section{Case 1}

A 72-year-old female patient with upper GI bleeding, she had history of pancreas CA, she transferred to Al-Najah Hospital because Wipple operation. But the operation was failed. After failed operation massive PE and Melina was developed Endoscopy was done and suggested that bleeding from $2^{\text {nd }}$ segment of duodenum. The Preoperative.: HgB: $6.8 \mathrm{~g} / \mathrm{dl}$ despite 28 unit of blood and plasma transfusion. Urgent selective angiography was done and suggested cutoff of superior pancreatic duodenal artery and coil Embolization was done the patient was discharged after 2 days with good condition and $\mathrm{HgB}$ level was $10.5 \mathrm{~g} / \mathrm{dl}$.

After 3 weeks repeat GIT bleeding was developed and $\mathrm{HgB}$ level was $8.3 \mathrm{~g} / \mathrm{dl}$, repeat Urgent selective angiography was done Embolization of gastro duodenal artery by Polyvinyl alcohol particle and coil Embolization was done the patient was discharged after 3 days with good condition and $\mathrm{HgB}$ level was $9.7 \mathrm{~g} / \mathrm{dl}$ (Figure 1).

\section{Case 2}

A 40-year-old female patient with thalasemia major and right hepatic mass presents with massive peritoneal bleeding from liver. The Pre-operative HgB:5.7 gram/dl, INR:2.84 despite 4 unit blood and 3 unit FFP transfusion. Left hepatic artery from celiac trunk and Right hepatic artery origin from proximal SMA. Urgent selective angiography was done and suggested Bleeding from RHA branches a srounding the mass in the right loupe of the liver. Absorbable gelatin sponge infusion and 3 Coil embolization was done (Figure 2). 


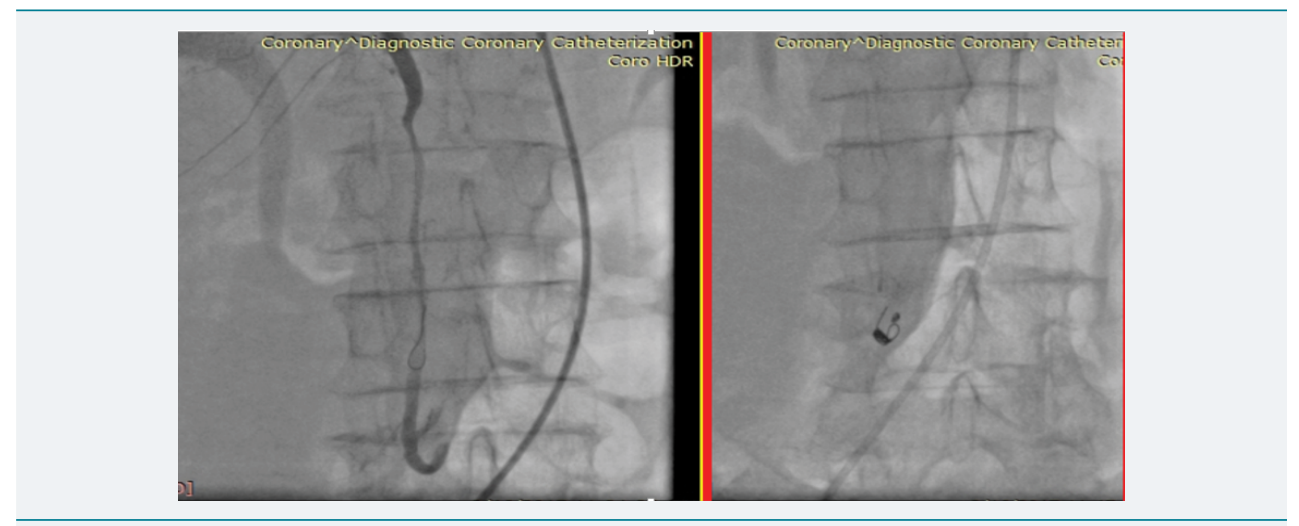

Figure 1: Before and after coil embolization of gastroduodenal artery.

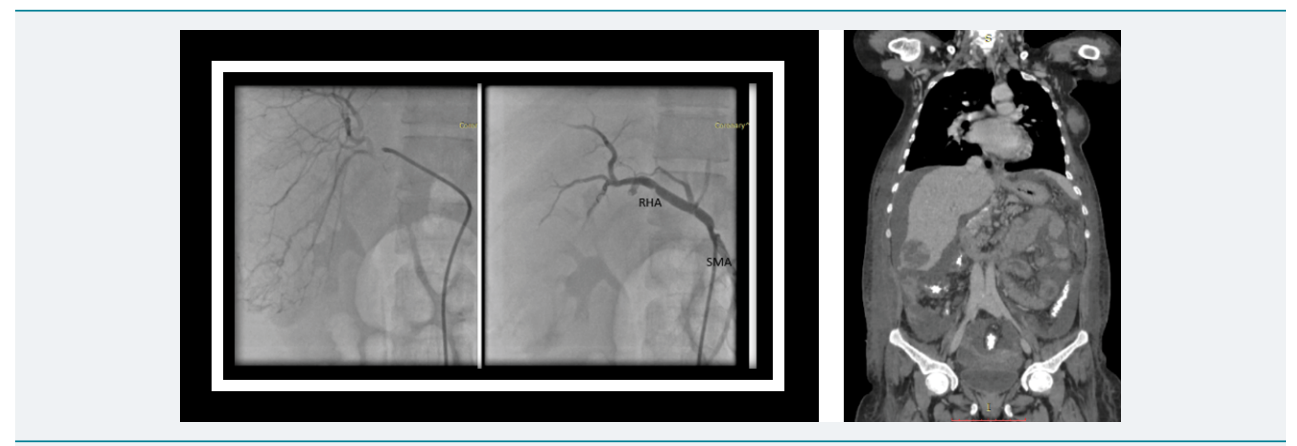

Figure 2: Right: before and after right hepatic artery embolization, left: MDCT: rupture liver cancer.

\section{Case 3}

Female patient 79 years old with CHF and chronic AF and with history of Cholesystoectomy before 7 years, Presentation with recurrent Upper GIT Bleeding. The Pre-operative HgB:6.7 gram/dl, despite 6unit blood and 3 unit FFP transfusion Urgent selective angiography was done and suggested right hepatic artery psedouanurysm. Coil Embolization was done and bleeding control was achieve. After 48 sudden detritions in vital sing was developed and cardiac arrest was developed (Figure 3).

\section{Case 4}

A 14-year-old man, who had no remarkable past illness, was injured in a motorcycleversus-vehicle crash and was transferred to our Emergency Department due to right upper abdominal pain. On arrival, his blood pressure was $110 / 70 \mathrm{mmHg}$, and heart rate was 96/min. Physical examination revealed right upper quadrant tenderness with muscular rigidity. Before the planned embolization procedure, the patient began experiencing abdominal pain nausea, and vomiting, Laboratory evaluation was notable for total bilirubin of $1 \mathrm{mg} / \mathrm{dL}$, international normalized ratio of $1.5 \mathrm{U}$, partial thromboplastin time of Laboratory data showed only mildly abnormal liver function tests and other biochemical studies were normal. A contrast-enhanced dynamic examination was performed with a MDCT (Sensation 124, Phillips). The arterial and the portal venous phase images were obtained at a 35 and $90 \mathrm{~s}$ delay after contrast injection. The MDCT scan disclosed a grade 4 liver injury and a 9x10 cm intrahepatic hematoma arising from the right hepatic artery. Coil Embolization was done and bleeding control was achieve (Figure 4).

\section{Case 5}

A 41 years old female patient with right upper quadrant pain and recurrent vomiting. The CT scan suggested very large liver hemangioma $(12 \times 11 \mathrm{~cm})$ transfer form general surgery because of in-op arterial embolization was done busing Absorbable gelatin sponge infusion and Coil embolization was done (Figure 5). 


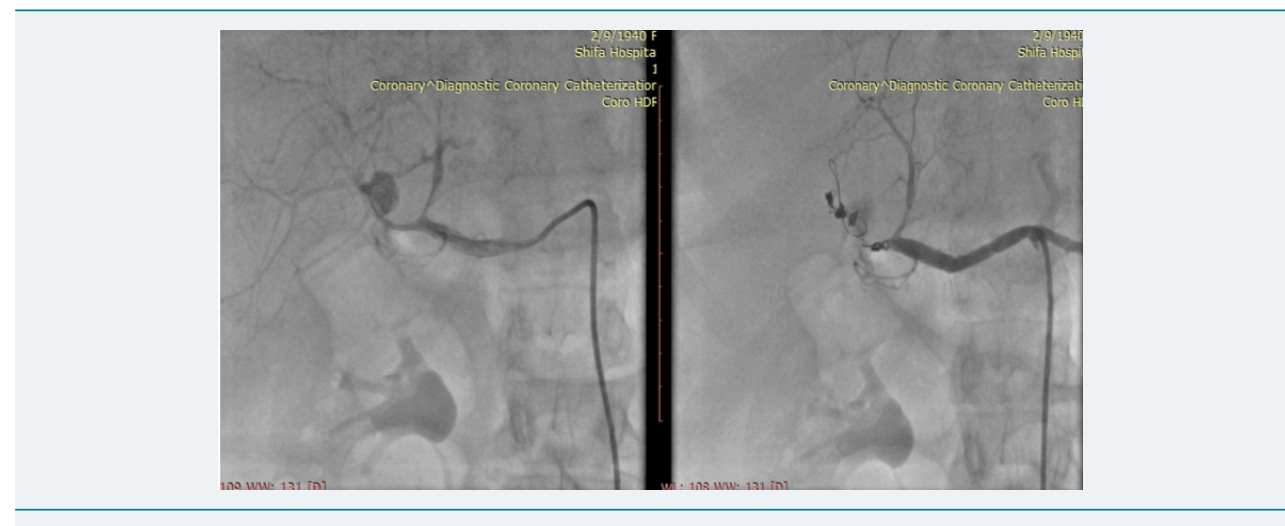

Figure 3: Before and after Coil Embolization for right hepatic artery psedouaneurysm.

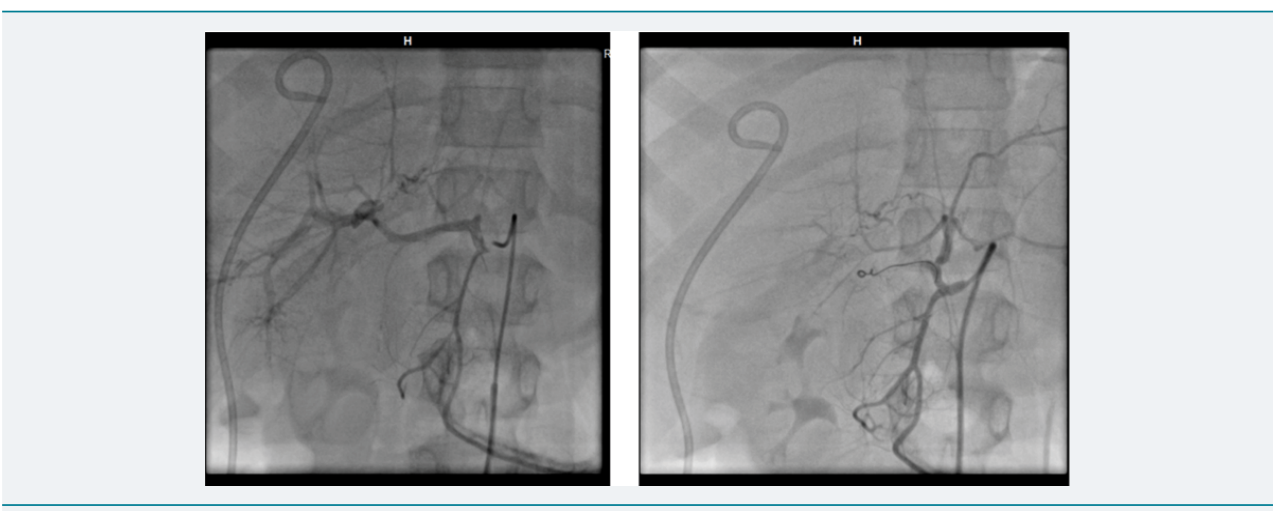

Figure 4: Right hepatic artery embolization for hepato-portal fistula.

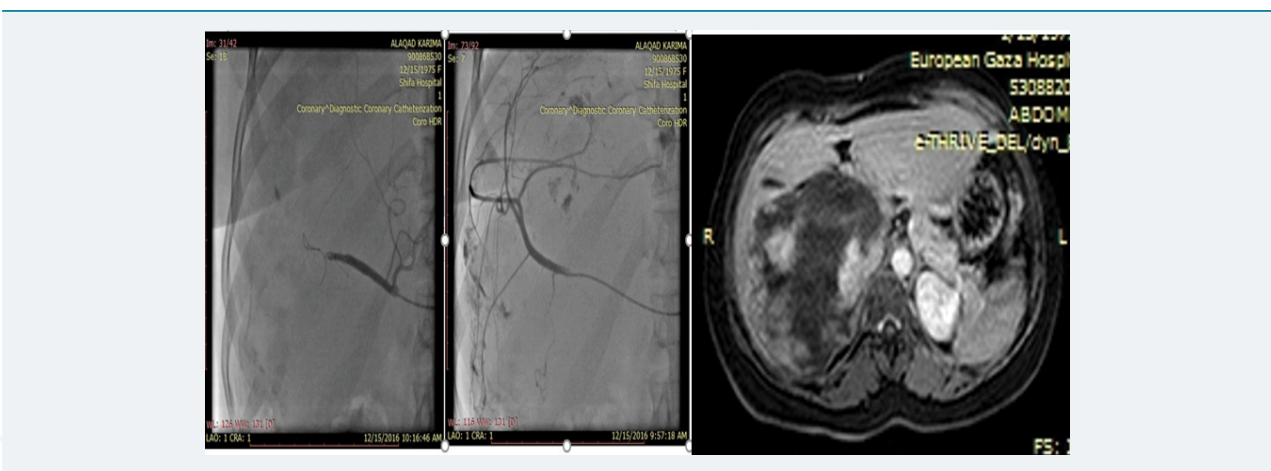

Figure 5: Right: before and after right hepatic artery embolization for large liver hemangioma, left: MDCT: large liver hemangioma.

\section{Discussion}

Endoscopic therapy is the recommended treatment of upper gastrointestinal bleeding [5]. Uncontrolled bleeding is still frequent, even though early endoscopy reduced mortality rates and repeated bleeding episodes.

Recent research suggetsed that TAE is a safe treatment method for gastrointestinal bleeding. Authors have reported satisfactory results of TAE compared to surgery for treatment of bleeding after gastric cancer resection, duodenal bleeding, severe bleeding of upper gastrointestinal tumors and bleeding gastroduodenal ulcers [6-10].

In our trial $(13 \%)$ of patients had an episode of rebleeding within 30 days after the embolization procedure. Dempsey et al., reported recurrent bleeding (30\%) after prophylactic gastroduodenal artery embolization [11]. repeated bleeding could be explained by the abundant collateral circulation of the duodenum, al-though inaccurate artery selection may also be responsible for higher rebleeding rates when performing a prophylactic embolization. 
Our trial $(20.0 \%)$ of the patients died. (one patient liver cancer, one patient pancreatic cancer and last patient right hepatic artery pseudoaneurysm). The mortality rate reported in our study is not different from rates reported in the literature $24 \%$ in Beggs et al.,28\% in Loffroy et al.) $[12,13]$.

Our patients did not present with any complications following the procedure due to the technical complications of TAE.

\section{Conclusion}

The results of this study suggest that, after failure of therapeutic endoscopy or high surgical risk for upper gastrointestinal bleeding, TAE should be the treatment of choice. TAE can also be used to effectively control bleeding after failed surgery or TAE. The safety and efficacy of TAE for the treatment of life-threatening, acute, nonvariceal upper GI bleeding is now widely accepted and is considered the gold standard for endoscopy-refractory patients.

\section{References}

1. Bjorkman DJ, Zaman A, Fennerty MB, Lieberman D, Disario JA, et al. Urgent vs. elective endoscopy for acute non-variceal upper Gl- bleeding: an effectiveness study. Gastrointest Endosc. 2004; 60: 1-8. Ref.: http://bit.ly/2XtVMmF

2. Higham J, Kang JY, Majeed A. Recent trends in admissions and mortality due to peptic ulcer in England increasing frequency of haemorrhage among older subjects. Gut. 2002; 50: 460-464. Ref.: http://bit.ly/2EXSNMp

3. Andersen IB, Bonnevie O, Jørgensen T, Sørensen TI. Time trends for peptic ulcer disease in Denmark, 1981-1993: analysis of hospitalization register and mortality data. Scand J Gastroenterol. 1998; 33 : 260-266. Ref.: http://bit.ly/2QYCy6w

4. Walt R, Katschinski $B$, Logan $R$, Ashley $J$, Langman $M$. Rising frequency of ulcer perforation in elderly people in the United Kingdom. Lancet. 1986; 1:489-492. Ref.: http://bit.ly/2HZ1ckh

5. Barkun AN, Bardou M, Kuipers EJ, Sung J, Hunt RH, et al. International consensus recommendations on the management of patients with non-variceal upper gastrointestinal bleeding. Ann Intern Med. 2010; 152: 101-113. Ref.: http://bit.ly/2wG3HBJ

6. Zandrino F, Tettoni SM, Gallesio I, Summa M. Emergency arterial embo-lization of upper gastrointestinal and jejunal tumors: an anal-ysis of 12 patients with severe bleeding. Diagn Interv Imaging. 2017; 98: 51-56. Ref.: http://bit.ly/2QUM1Mc

7. Park S, Shin JH, Gwon DI, Kim HJ, Sung KB, et al. Transcatheter Arterial Embolization for Gastrointestinal Bleeding Associated with Gastric Carcinoma: Prognostic Factors Predicting Successful Hemostasis and Survival. J Vasc Interv Radiol. 2017; 28: 1012-1021. Ref.: http://bit.ly/2WkHsvB

8. Nykänen T, Peltola E, Kylänpää L, Udd M. Bleeding gastric and duodenal ulcers: case-control study comparing angioembolization and surgery. Scand J Gastroenterol. 2017; 52: 523-530. Ref.: http://bit.ly/2ZfdOFc

9. Yang J, Zhang $\mathrm{XH}$, Huang $\mathrm{YH}$, Chen $\mathrm{B}, \mathrm{Xu} \mathrm{JB}$, et al. Diagnosis and treatment of abdominal arterial bleeding after radical gastrectomy: a ret-rospective analysis of 1875 consecutive resections for gastric cancer. J Gastrointest Surg. 2016; 20: 510-520. Ref.: http://bit.ly/2K2dN8F

10. Bagdasarov VV, Bagdasarova EA, Chernookov Al, Ataian AA, Karchevskiĭ EV, et al. Endovascular arterial embolization for duodenal bleeding as an alternative to surgical approach. Khirurgiia (Sofiia). 2016; 2: 45-50. Ref.: http://bit.ly/2WM8laH

11. Dempsey DT, Burke DR, Reilly RS, McLean GK, Rosato EF. Angiography in poor-risk patients with massive nonvariceal upper gastrointestinal bleeding. Am J Surg. 1990; 159: 282-286. Ref.: http://bit.ly/2EXqLAn

12. Beggs AD, Dilworth MP, Powell SL, Atherton $H$, Griffiths EA. A systematic review of transarterial embolization versus emergency surgery in treat-ment of major nonvariceal upper gastrointestinal bleeding. Clin Exp Gastroenterol. 2014; 7: 93-104. Ref.: http://bit.ly/2QQk0oX

13. Loffroy R, Rao P, Ota S, De Lin M, Kwak BK, et al. Embolization of acute nonvarice-al upper gastrointestinal hemorrhage resistant to endoscopic treatment: results and predictors of recurrent bleeding. Cardio-vasc Intervent Radiol. 2010; 33: 1088-1100. Ref.: http://bit.ly/2WLHpgE 